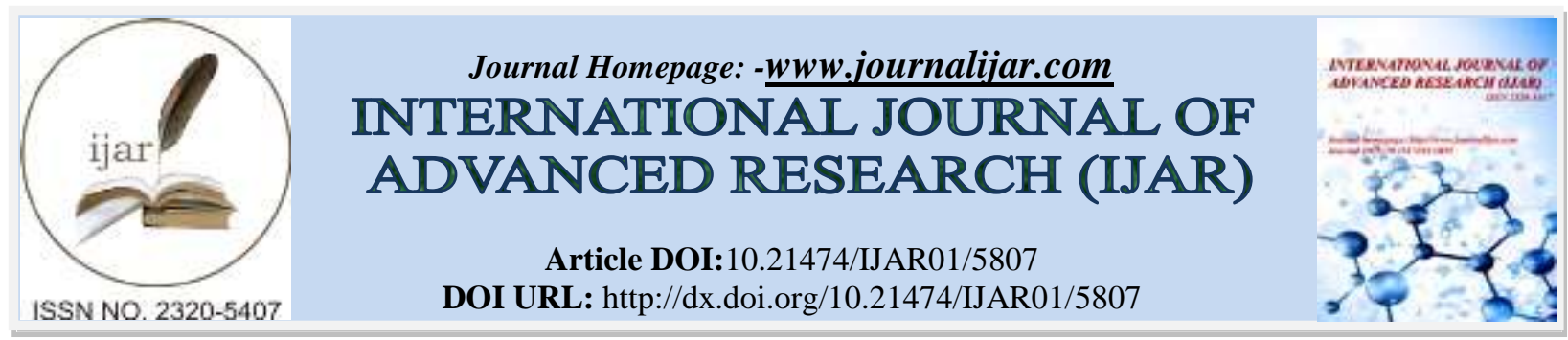

RESEARCH ARTICLE

\title{
AIR POLLUTION TOLERANCE INDEX (APTI) OF SELECTED PLANTS NEAR BHUSAN SPONGE IRON INDUSTRY LOCATED IN RENGALI BLOCK OF SAMBALPUR DISTRICT, ODISHA, INDIA.
}

Sasmita Dash and "Sunanda Sahoo.

School of Life Sciences Sambalpur University, Jyoti Vihar-768019. Burla, Odisha, India.

\section{Manuscript Info}

Manuscript History

Received: 08 September 2017

Final Accepted: 10 October 2017

Published: November 2017

Key words:-

Sink, bio indicator, tolerant, sensitive, intermediate.

\begin{abstract}
In this paper the air pollution tolerance index (APTI) of twenty plant species near BPSL (Bhushan Power and Steel Ltd.) Rengali, Sambalpur were investigated. Screening of plants for their sensitivity/tolerance level to air pollutants is important because the sensitive plants can serve as bio-indicator and the tolerant plants as sink for controlling air pollution in industrial areas. In order to evaluate the susceptibility level of plants to air pollutants, four parameters namely total chlorophyll, ascorbic acid, $\mathrm{pH}$ of leaf extract and relative water content were determined and computed to signify APTI . The results showed that at experimental plot the most tolerant species with respects to APTI are Mangifera indica, Calotropis procera, Lantana camara, and Dalbergia sisoo. The plant species like Eucalyptas citriodora, Ficus religiosa, Delonix regia, Ficus bengalnesis, Madhuca indica, Aegle marmelos, Liziphus julyuba, Ailanthus excels, Diospyros melanoxylon, Shorea robusta, Butea monosperma, Bombax ceiba, Azadirachta indica, Artocarpus heterophyllus are intermediately tolerant where as Buchania lanzan and Tabernaemontana divaricata where categorized as sensitive species. The same was recorded for plants of control plot but with a lower APTI value, except Bombax ceiba which was considered as sensitive species. The present study suggests that evaluation of plant tolerance and performance index might be very useful in selection of appropriate species for the development of green belt in the vicinity of industrial areas.
\end{abstract}

Copy Right, IJAR, 2017,. All rights reserved.

\section{Introduction:-}

With the fast growing and excessive increase in industrialization, pollution is also increasing day by day. Plant species can be effectively used as filters for reducing air pollution and also as bio-indicators of urban air quality. Leaf is the plant part which is most sensitive and constantly exposed to air pollution. Plants absorb pollutants into their system, but they also have some tolerance limit and tend to show symptoms of damage after prolonged exposure. Based on the absorbing power and tolerance limit, plant can be categorized as highly tolerant, intermediate, sensitive and very sensitive species.

This has been incorporated by scientists into a quantitative value of air pollution tolerance index (APTI), depending $\mathrm{pH}$, Relative water content, Ascorbic acid content and chlorophyll content. 
The particulate and gaseous pollutants alone and in combination can cause serious setbacks to the overall physiology of plants (Ashenden and Williams, 1980; Mejstrick, 1980; Anda, 1986). Regional impact of air pollution on local plant species is one of the major ecological issues. The climate condition, the physico -chemical properties of air pollutants and their residence time in the atmosphere have the impact on surrounding plants and animals. (Wagh et al., 2006). Trees experience the greatest exposure and are influenced greatly by pollutants concentration due to their perennial nature (Raina and Sharma, 2003).

Since the tolerance and sensitivity of plants towards air pollutants varies, the categorization of plants into sensitive and tolerant groups will be helpful as the former can be used as indicators of pollutants and the later as sinks for the pollutants to reduce air pollution in the industrial areas which may be contaminated with several pollutants. Presence of trees in such environment can improve air quality through enhancing the uptake of gases and particles. However, this function of pollution abatement is best performed by the pollution tolerant species (Das and Prasad, 2010).

In order to evaluate the ability of plants to absorb such pollutants the APTI of twenty economically important tree species were determined around Bhusan Industrial complex present in Rengalli Block of Sambalpur district, Odisha, India in the radius of $5 \mathrm{KM}$ for the point source during the month of April 2014. The goal of this study was to develop a gradation of APTI that can be applied broadly in the selection of species in urban planting; to find out the tolerance as well as sensitivity of the common plants species subjected to industrial pollution and to identify species, tolerant and sensitive to pollutants that can be used to develop green belt around the industrial areas. It appears that plantation in industrial areas is a site specific activity and knowledge of tolerance level of plant species to air pollution is necessary (Das et al., 2010).

Air pollution toleration index (APTI) is an index which denotes capability of a plant to combat against air pollution. Plants which have higher APTI value are tolerant to air pollution and can be used as sink to mitigate pollution, while plants with low index value show less tolerance and can be used to indicate level of air pollution (Singh and Rao, 1983).

The ability of each plant species to absorb and adsorb pollutants by their foliar surface varies greatly and depends on several chemical, physiological, and morphological characteristics (Singh and Verma, 2007). The sensitive species help to indicate air pollution and tolerant ones help in abatement of air pollution and therefore a number of environmental benefits can be obtained by planting tolerant species in polluted areas. For this purpose, evaluation of plants with respect to their tolerance level to air pollution may be essential (Lakshmi et al., 2009).

It is evident that the plant species with highest amount of air pollution tolerance index (APTI) can withstand highest pollution environment where as plant species with low air pollution tolerance index have lower capacity to combat against air pollution induced by industries ( Suvarna Lakshmi et al ., 2008; Tnambavani et al .,2011).

The present study has been undertaken:

1. To study the effect of ambient particulates and gaseous pollutants on physiological attributes and air pollution tolerance index (APTI) of certain plant species. To evaluate the APTI of 20 common tree plant species of more polluted site (near Bhusan sponge iron plant) and compare with control i.e. less polluted site (Dhanupali, Sambalpur).

2. To identify tolerant species with respect to variation in four biochemical parameters and this may help in proper species selection in industrial areas.

\section{Materials and Methods:-}

\section{Study site:-}

Experimental site was located in the neighborhood of Bhusan power and steel plant, Rengali, Sambalpur, Odisha, India. The steel plant is located between Latitude $20^{\circ} 44^{\prime}$ to $21^{\circ} 41^{\prime} \mathrm{N}$ and longitudes $84^{\circ} 01^{\prime}$ to $84^{\circ} 03^{\prime} \mathrm{E}$. The study sites of the present investigation were Experimental sites (highly polluted) around $5 \mathrm{~km}$ periphery of the Bhushan Plant and Control site (unpolluted) was Dhanupali, way to Dhama road, Sambalpur, Odisha, India.

\section{Leaf Sample Collection:-}

Twenty dominant tree species present in the above mentioned area were selected for the present study. Care was taken to collect fresh leaves from each plant in triplicates. Matured leaves from these plants were randomly collected 
from the sampling sites with similar light, water and soil condition and immediately taken to the laboratory for analysis; leaf fresh weight was taken immediately upon returning to the laboratory. Dry weight was taken to express ascorbic acid content and total chlorophyll content on dry leaf weight basis. Samples were preserved at $4^{\circ} \mathrm{C}$ till the analysis of ascorbic acid; total chlorophyll and leaf extract $\mathrm{pH}$.

Air pollution tolerance index (APTI) was determined by measuring the factors such as ascorbic acid, total chlorophyll, leaf extract $\mathrm{pH}$ and relative water contents of leaf samples.

Relative Water Content:-

Leaf RWC (Relative water Content) is determined by using the method described by Liu and Ding (2008) and calculated with the formula $\mathrm{RWC}=(\mathrm{WF}-\mathrm{WD}) \times 100 /(\mathrm{WT}-\mathrm{WD})$

WF- Fresh weight of leaf

WD - Dry weight of leaf

WT - Turgid weight of leaf

Fresh weight of leaf was recorded by weighing the fresh leaves. To get the dry weight the leaves are dried in an oven at $70^{\circ} \mathrm{C}$ for overnight and then the dry weight was taken. For obtaining the turgid weight, the leaves are immersed in water over night, blotted dry and then weighed.

\section{Leaf extract pH:-}

Five grams of fresh leaves are homogenized in $10 \mathrm{ml}$ of deionised water. This is filtered and $\mathrm{pH}$ of the leaf extract was determined using digital calibrated $\mathrm{pH}$ meter.

\section{Total Chlorophyll Content:-}

For the total chlorophyll determination $0.5 \mathrm{~g}$ fresh leaf material was ground and diluted in $10 \mathrm{ml}$ of distilled water. A subsample of $2.5 \mathrm{ml}$ was mixed in $10 \mathrm{ml}$ acetone and left to stand for $15 \mathrm{~min}$. It was filtered and centrifuged at 2500 rpm for $3 \mathrm{~min}$. Optical density of the supernatant was read at $645 \mathrm{~mm}$ (D645) and $663 \mathrm{~nm}$ (D663) using a digital spectrophotometer. Optical density of the total chlorophyll (OT) is the sum of the chl-a (D645) density and Chlb (D $663)$ density.

Thus, OT $=20.2(\mathrm{D} 645)+8.02(\mathrm{D} 663)$

Total Chlorophyll (mg/gm dry wt.) $=0.1$ OT x (leaf dw/leaf fw)

\section{Analysis of Ascorbic acid content:-}

$1 \mathrm{~g}$ of fresh leaf sample were taken and homogenized with distilled water and volume was measured. To $25 \mathrm{ml}$ of diluted sample $2.5 \mathrm{ml}$ of $5 \%$ Meta phosphoric acid was added. Then 2 drops of bromine water was added to oxidize the ascorbic acid in its dihydro form. The solution was centrifuged for $5 \mathrm{~min}$ and supernatant was collected to estimate the ascorbic acid content by spectrophotometric method at $540 \mathrm{~nm}$ after incubation at $37^{\circ} \mathrm{C}$ for $3 \mathrm{hr}$. followed with the addition of concentrated $\mathrm{H}_{2} \mathrm{SO}_{4}$.

\section{Calculation of APTI:-}

The APTI was calculated by using the following formula (Liu and Ding, 2008).

$\mathrm{APTI}=\frac{A(T+P)+R}{10}$

Where $\mathrm{A}=$ Ascorbic acid $(\mathrm{mg} / \mathrm{g})$

$\mathrm{P}=\mathrm{pH}$ of leaf extract

$\mathrm{T}=$ Total chlorophyll $(\mathrm{mg} / \mathrm{g})$

$\mathrm{R}=$ Relative water content $(\%)$

Gradation of APTI was done by dividing APTI values into four grades such as - Tolerant, Intermediate, Sensitive and very sensitive.

\footnotetext{
APTI Index range:-

$<1=>$ very sensitive

1 to $16=$ Sensitive

17 to $29=>$ Intermediate

30 to $100=>$ Tolerant
} 


\section{Results:-}

In the present investigation a total of twenty tree species were identified within $5 \mathrm{Km}$ radius of Bhusan power and steel plant and presented in Table - I along with their common names and families. Since APTI values are attributed to the different responses of the plants to the four physiological factors, namely ascorbic acid, total chlorophyll, $\mathrm{pH}$ of the leaf extract and the relative water content of the leaf, these findings are as follows.

\section{Changes in Relative water content:-}

Relative water content of a leaf is the water present in its relative to full turgidity. High water content within plant body serves as an indicator of drought resistance in plants and helps to maintain its physiological balance under stress conditions such as exposure to air pollution when transpiration rates are usually high (Dedio, 1975). The results of the present investigation showed that, RWC of all plant species of control site varies from 50.38 to 87.96 $\mathrm{mg} / \mathrm{g}$ and 56.45 to $89.29 \mathrm{mg} / \mathrm{g}$ of experimental site (fig-1).

\section{Changes in Ascorbic Acid Content:-}

Ascorbic acid, a natural antioxidant has been shown to play an important role in pollution tolerance; it activates many physiological and defense mechanism in plants (Chen et al., 1990). It is directly or indirectly concerned with the photosynthetic reactions. Ascorbic acid content of all the species may be due to the rate of production of ROS (Reactive Oxygen Species) such as $\mathrm{SO}_{2}, \mathrm{HSO}_{3}, \mathrm{OH}$ and $\mathrm{O}_{2}$ etc. during photo-oxidation of $\mathrm{SO}_{3}$ and $\mathrm{SO}_{4}(\mathrm{Agrawal}$, 2003). In present study the ascorbic acid content of control plants varies from 4.96 To $15.85 \mathrm{mg} / \mathrm{g}$ and experimental plant from 5.3 To $17.23 \mathrm{mg} / \mathrm{g}$, thus revealed a great deal of variation in the levels of ascorbic acid in all the plant species of experimental site (Fig-2).

\section{Changes in leaf extract $\mathrm{pH}:-$}

The $\mathrm{pH}$ of the leaf extract varied significantly in the present investigation. The $\mathrm{pH}$ of leaf extract ranged from 4.87 to 7.77 in experimental site plants where as those from the non industrial (control) site ranges from 5.78 to 7.77 showed $\mathrm{pH}$ neutral to slightly alkaline range (Fig-3) Rai et al. (2013) observed pH ranging 5.0 to 7.0 in industrial site and that of the control site from 6.0 to 9.0 in non industrial site.

\section{Changes in total chlorophyll content:-}

It is well evident that chlorophyll content of plants varies from species to species; age of leaf and also with the pollution level. (Katiyar and Dubey, 2001). The higher levels of total chlorophyll content of plants species may be due to its tolerance nature. (Beg et al., 1990 and Jyoti and Jaya, 2010) Therefore, pants maintaining their chlorophyll contents even under polluted environment are said to be tolerant ones (Singh and Verma, 2007). In the present study the total chlorophyll contents of control site plants ranges from 7.71 to $14.8 \mathrm{mg} / \mathrm{g}$ and in experimental site plants from 8.04 to $15.0 \mathrm{mg} / \mathrm{g}$ (Fig-4).

Air pollution tolerance index (APTI) :-

In the present work the results of APTI calculated for the twenty plant species studied at different sites (control and experimental site) is mentioned in Table- 2.

Calotropis procera, Lantana camara, Dalbergia sisoo, Magifera indica exhibited the highest APTI and found to show tolerant response whereas Eucalyptus citridora, Ficus religiosa, Delonix regia, Ficus bengalensis, Madhuca indica, Aegle marmelos, Ziziphus jujuba, Ailanthus excels, Diospyrus melanoxylon,Shorea robusta, Butea monosperma, Bombax caiba, Azadirachta indica, Artocarpus heterophyllus, can be considered to show intermediate response and lastly Buchania lanzen and Tabernaemontana diavericata can be considered to show sensitive response. The same was recorded for plants of control plot but with a lower APTI value except Bombax ceiba which was exhibited as sensitive species.

Tab-1:-List of leaf samples collected from twenty plant species

\begin{tabular}{|l|l|l|l|}
\hline $\begin{array}{l}\text { SL.N } \\
\text { O }\end{array}$ & $\begin{array}{l}\text { LOCAL NAME OF THE } \\
\text { SPECIES }\end{array}$ & SCENTIFIC NAME OF THE SPECIES & FAMILY \\
\hline 1 & NILAGIRI & EUCALYPTAS CITRIODORA & MYRTACEA \\
\hline 2 & MANGO & MANGIFERA INDICA & ANACARDIACEAE \\
\hline 3 & PEEPAL & FISCUS RELIGIOSA & MORACEAE \\
\hline 4 & KRUSHNA CHUDA & DELONIX REGIA & CEASALPINACEAE \\
\hline
\end{tabular}




\begin{tabular}{|l|l|l|l|}
\hline 5 & ARAKHA & CALOTROPIS PROCERA & ASCLEPIADACAE \\
\hline 6 & BANYAN & FISCUS BENGALENSIS & MORACEAE \\
\hline 7 & MAHUA & MADHUCA INDICA & SAPOTACEAE \\
\hline 8 & BELA & AEGLE MARMELOS & RUTACEAE \\
\hline 9 & KOLI & ZIZIPHUS JUJUBA & VHMNACEAE \\
\hline 10 & LANTANA & LANTANA CAMARA & SIMARUBACEAE \\
\hline 11 & MAHALIMB & AILANTHUS EXCELSA & EBENACEAE \\
\hline 12 & KENDU & DIOSPYROS MELANOXYLON & DIPLTEROCARPACEAE \\
\hline 13 & SAL & SHOREA ROBUSTA & FABACEAE \\
\hline 14 & PALASA & BUTEA MONOSPERMA & APOCYNACEAE \\
\hline 15 & CURE & TABERNAEMONTANA DIVARICATA & ANACARDIACEAE \\
\hline 16 & CHAR & BUCHANIA LANZEN & BOMBACACEAE \\
\hline 17 & SIMILI & BOMBAX CEIBA & FABACEAE \\
\hline 18 & SISHOO & DALBERGIA SISOO & MELIACEAE \\
\hline 19 & NEEM & AZADIRACHTA INDICA & MORACEAE \\
\hline 20 & PANASA & ARTOCARPUS HETEROPHYLLUS & \\
\hline
\end{tabular}

Tab 2:-Air pollution tolerance index of plants of control plot and experimental plot

\begin{tabular}{|c|c|c|c|c|c|c|c|c|}
\hline $\begin{array}{l}\text { SL. } \\
\text { NO. }\end{array}$ & LOCAL NAME & SITE & A & $\mathbf{P}$ & $\mathbf{T}$ & $\mathbf{R}$ & APTI & $\begin{array}{l}\text { GRADATIO } \\
\text { N OF APTI }\end{array}$ \\
\hline \multirow[t]{2}{*}{1} & NILGIRI & EXPERIMENTAL & 8.76 & 5.12 & 9.55 & 72.1 & 20.05 & $\mathrm{I}$ \\
\hline & & CONTROL & 7.43 & 6.4 & 8.36 & 69.8 & 17.94 & I \\
\hline \multirow[t]{2}{*}{2} & MANGO & EXPERIMENTAL & 9.64 & 7.3 & 15 & 85.8 & 30.08 & $\mathrm{~T}$ \\
\hline & & CONTROL & 9.58 & 7.71 & 14.8 & 84.4 & 30.07 & $\mathrm{~T}$ \\
\hline \multirow[t]{2}{*}{3} & PEEPAL & EXPERIMENTAL & 9.81 & 4.88 & 12 & 83.4 & 24.91 & I \\
\hline & & CONTROL & 8.26 & 5.78 & 10.2 & 81.2 & 21.29 & $\mathrm{I}$ \\
\hline \multirow[t]{2}{*}{4} & $\begin{array}{l}\text { KRUSHNACH } \\
\text { UDA }\end{array}$ & EXPERIMENTAL & 7.17 & 5.16 & 12.3 & 73.7 & 19.92 & I \\
\hline & & CONTROL & 6.22 & 6.23 & 10.2 & 70.7 & 17.26 & I \\
\hline \multirow[t]{2}{*}{5} & ARAKHA & EXPERIMENTAL & 17.23 & 7.16 & 10.1 & 79.1 & 37.66 & $\mathrm{~T}$ \\
\hline & & CONTROL & 15.85 & 7.77 & 9.81 & 75.8 & 35.44 & $\mathrm{~T}$ \\
\hline \multirow[t]{2}{*}{6} & BANYAN & EXPERIMENTAL & 9.8 & 4.97 & 10.6 & 76.6 & 22.87 & I \\
\hline & & CONTROL & 8.2 & 5.9 & 10.2 & 74.4 & 20.66 & I \\
\hline \multirow[t]{2}{*}{7} & MAHUA & EXPERIMENTAL & 9.98 & 5.41 & 12.3 & 79.2 & 25.55 & $\mathrm{I}$ \\
\hline & & CONTROL & 8.81 & 6.43 & 10.8 & 77.2 & 22.93 & I \\
\hline \multirow[t]{2}{*}{8} & BELA & EXPERIMENTAL & 7.3 & 5.14 & 11.8 & 81.2 & 20.45 & $\mathrm{I}$ \\
\hline & & CONTROL & 6.2 & 6.2 & 10.3 & 80.4 & 18.29 & I \\
\hline \multirow[t]{2}{*}{9} & KOLI & EXPERIMENTAL & 9.68 & 5.83 & 10.2 & 56.5 & 21.16 & $\mathrm{I}$ \\
\hline & & CONTROL & 8.85 & 6.36 & 10 & 50.4 & 19.51 & I \\
\hline \multirow[t]{2}{*}{10} & LANTANA & EXPERIMENTAL & 15.76 & 7.77 & 9.81 & 75.8 & 35.28 & $\mathrm{~T}$ \\
\hline & & CONTROL & 12.23 & 8.14 & 10.2 & 80 & 30.46 & $\mathrm{~T}$ \\
\hline \multirow[t]{2}{*}{11} & MAHALIMB & EXPERIMENTAL & 9.57 & 5.91 & 14.6 & 86.6 & 28.24 & $\mathrm{I}$ \\
\hline & & CONTROL & 8.44 & 6.31 & 12.9 & 83.3 & 24.5 & I \\
\hline \multirow[t]{2}{*}{12} & KENDU & EXPERIMENTAL & 9.73 & 6.11 & 12.1 & 77 & 25.4 & I \\
\hline & & CONTROL & 8.11 & 7.01 & 10.3 & 72.1 & 21.23 & I \\
\hline \multirow[t]{2}{*}{13} & SAL & EXPERIMENTAL & 9.62 & 4.87 & 14.3 & 77.3 & 26.14 & I \\
\hline & & CONTROL & 9.21 & 7.11 & 11.2 & 82.2 & 25.04 & I \\
\hline \multirow[t]{2}{*}{14} & PALASA & EXPERIMENTAL & 9.2 & 5.62 & 12.5 & 67.5 & 23.41 & I \\
\hline & & CONTROL & 7.78 & 6.73 & 11.2 & 60.6 & 19.98 & I \\
\hline \multirow[t]{2}{*}{15} & CURE & EXPERIMENTAL & 6.28 & 5.6 & 8.04 & 80.8 & 16.64 & $\mathrm{~S}$ \\
\hline & & CONTROL & 6 & 6.48 & 7.71 & 79.3 & 16.44 & $\mathrm{~S}$ \\
\hline \multirow[t]{2}{*}{16} & CHAR & EXPERIMENTAL & 5.78 & 5.47 & 9.56 & 81 & 16.79 & $\mathrm{~S}$ \\
\hline & & CONTROL & 5.71 & 6.93 & 8.21 & 79 & 16.54 & $\mathrm{~S}$ \\
\hline 17 & SIMILI & EXPERIMENTAL & 5.3 & 5.21 & 17.7 & 79.5 & 18.52 & I \\
\hline
\end{tabular}




\begin{tabular}{|l|l|l|l|l|l|l|l|l|}
\hline & & CONTROL & 4.96 & 6.45 & 12.5 & 77.2 & 16.89 & S \\
\hline 18 & SISHOO & EXPERIMENTAL & 11.21 & 5.96 & 13.8 & 89.3 & 31.09 & T \\
\hline & & CONTROL & 10.85 & 6.98 & 12.7 & 88 & 30.09 & T \\
\hline 19 & NEEM & EXPERIMENTAL & 9.43 & 5.22 & 12 & 76.1 & 28.78 & I \\
\hline & & CONTROL & 8.11 & 6.27 & 10.1 & 80.7 & 21.35 & I \\
\hline 20 & PANASA & EXPERIMENTAL & 9.34 & 5.15 & 11.7 & 86.1 & 24.34 & I \\
\hline & & CONTROL & 8.11 & 6.88 & 10.2 & 82.4 & 22.09 & I \\
\hline
\end{tabular}

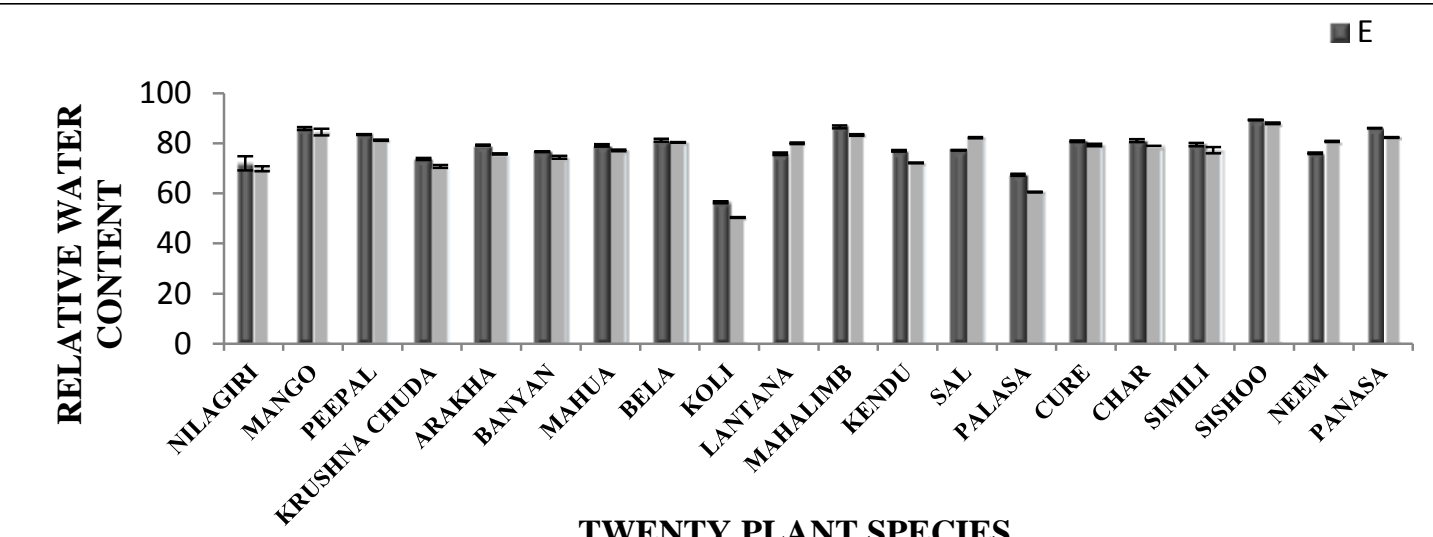

TWENTY PLANT SPECIES

Fig-1:- RWC of all plant species of control site (C) and experimental site (E).

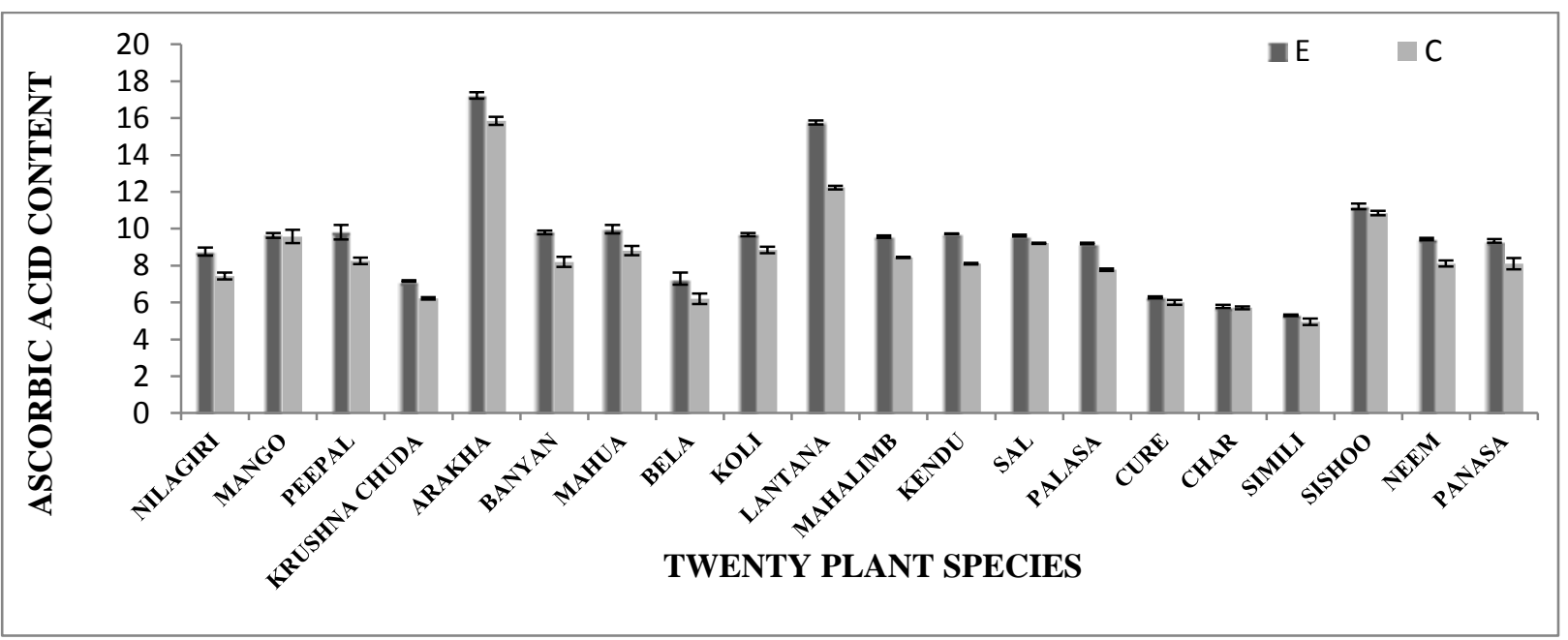

Fig-2:- Ascorbic acid content of all plant species of control site (C) and experimental site (E). 


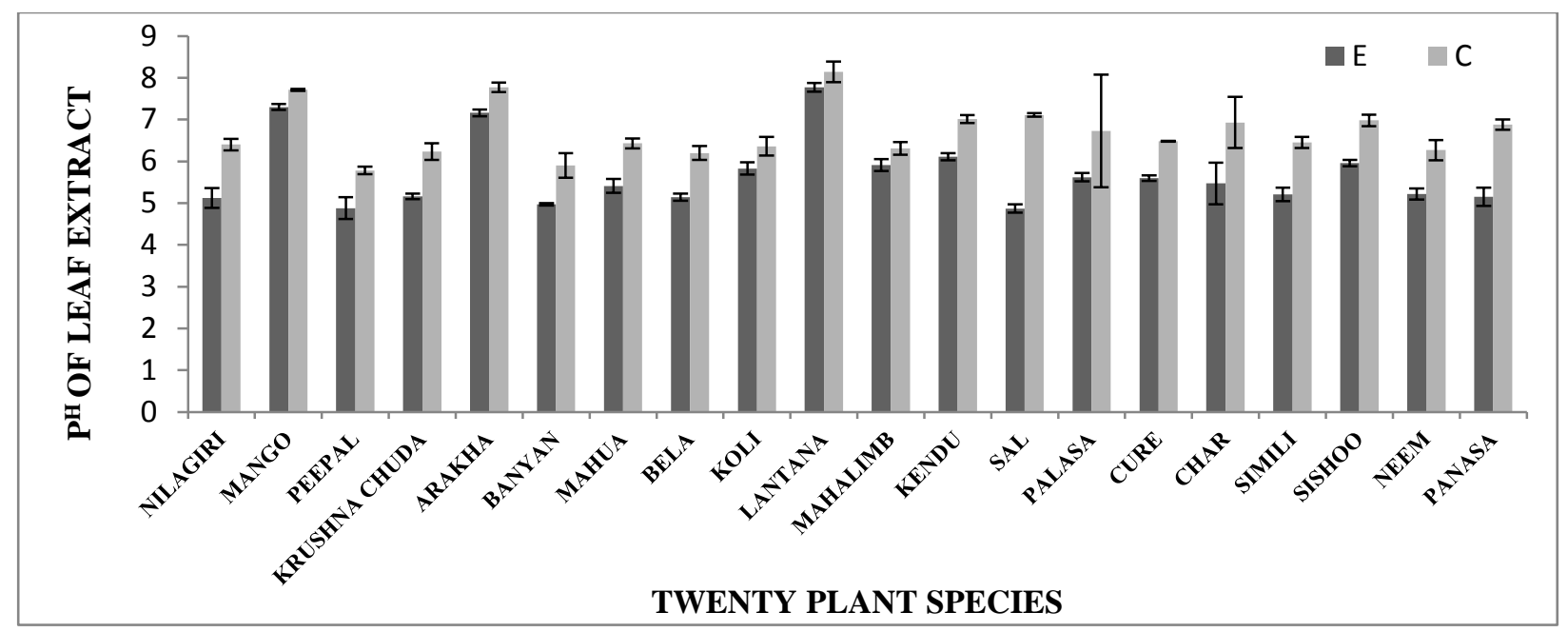

Fig 3:- $\mathrm{pH}$ of leaf extracts of all plant species of control site (C) and experimental site (E).

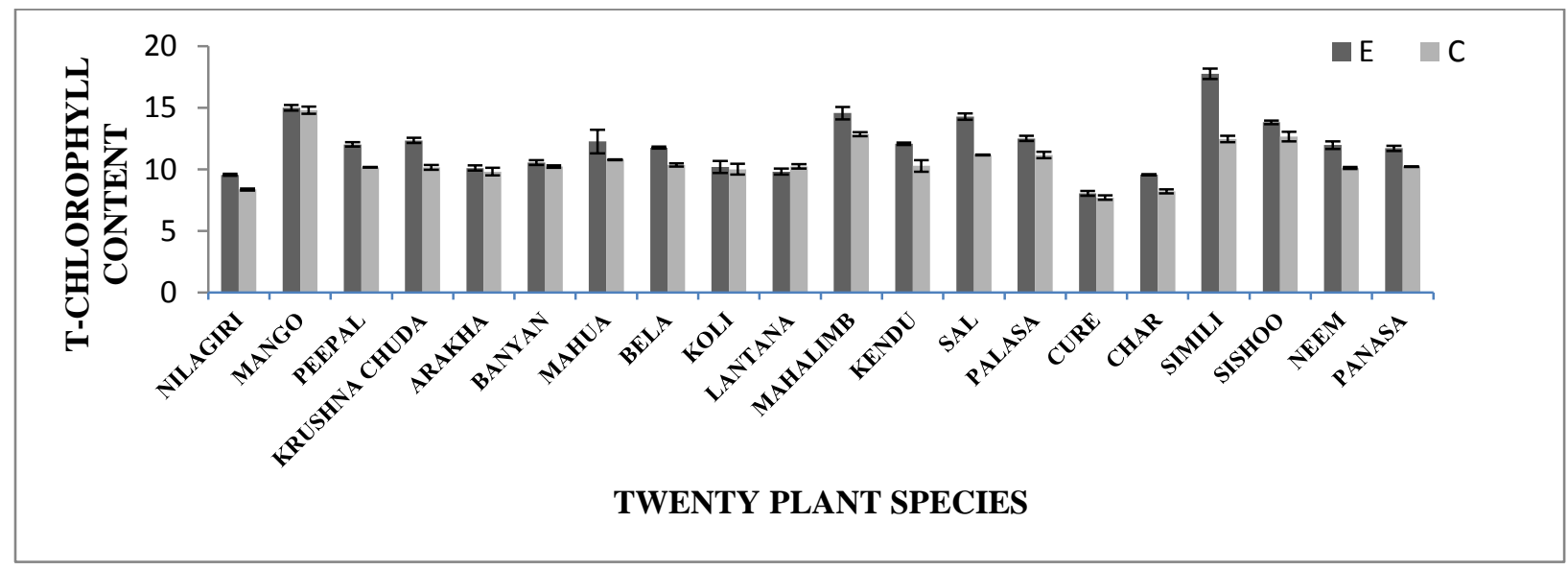

Figure 4:- Total chlorophyll contentof all plant species of control site (C) and experimental site (E)

\section{Discussion:-}

In the present study the relative water content of the leaves from the polluted area was found to be higher than those from the control plants. It is similar to the report of Agbaire and Esiefarienhe (2009), Gharge and menon (2012) and Rai et al., (2013), who found higher RWC in experimental plants than in the control plants. The increased RWC in plants of experimental site may be due to maintenance of physiological balance in stress conditions such as exposure to air pollution. The level of ascorbic acid was more in the leaves of experimental sites than that of control site.This increase may be due to increased rate of production of ROS due to air pollution (Pierre and Queirz, 1981). Increased level of ascorbic acid may be due to the defense mechanism of the plants. This is in aggrement with the reports of Chandawat et al. (2011), Meerabai et al. (2012) and Rai et al. (2013) who found higher level of ascorbic acid in the leaves of the most tolerant plants at the polluted sites and this suggests their tolerance to the air pollutants. The lower ascorbic acid in the leaves of the sensitive ones shows the sensitive nature of the plants to the pollutants. $\mathrm{pH}$ is a biochemical parameter that acts as an indicator for sensitivity to air pollution. (Scholz and Reck, 1977). High pH may increase the efficiency of conversion from hexose sugar to ascorbic acid (Escobedo et al., 2008) while low leaf extract $\mathrm{pH}$ showed good correlation with sensitivity to air pollution (Yan and Hui, 2008). In the present work, the total chlorophyll of the experimental plants was higher than those of the control plants, Agbaire and Esiefarienrhe, (2009) reported similar results in their work. Jyoti and Jaya (2010) demonstrated higher levels of total chlorophyll in the leaves of polluted area and opined that this may be due to tolerant nature of the plants. Chandawat et al. (2011) observed that the chlorophyll content of all the plants they tested varied with the pollution status of the area; as well as the tolerance and sensitivity of the plants species. Screening of plants based on their susceptibility level is important .The evaluation of plant response based on single criterion is not convenient, therefore determination of APTI, based on four parameters give more reliable result. Findings on APTI showed variation in plants of polluted 
areas.The variations in the biochemical parameters can be used as a marker for early diagnosis of air pollution stress prior to the onset of visible injury symptoms. Air pollution tolerance index is affected by natural climatic conditions such as rainfall, temperature, soil type; relative humidity etc. and these were not taken into consideration in this work, since all the experimental plants were collected from the same climatic environment. Rai et al., (2013) suggested APTI to be an inherent quality of plants to encounter air pollution stress.

\section{Conclusion:-}

The APTI determination provides a reliable method for screening large no. of plants with respect to their susceptibility to air pollutants. Tolerance of plants may be specific to the site depending on the level of pollution. Plants growing in the industrialized area showed higher APTI than those at the non industrial site. Plant species such as Mangifera indica, Calotropis procera, Dalbergia sisoo, Lantana camara that are tolerant to air pollution can absorb air pollutants, particulate matter and other emissions, thereby can improve the air quality. Such plants should be planted around industrial areas. Sensitive plants such as Buchania lanzan, Tabernaemontana divericata are more useful as bioindicators as recommended by Agrawal et al. (1991) which indicate the pollution status of a particular area. The plantation of tolerant plants in large scale can reduce the air pollution near the Bhushan sponge iron industry and can give a clean environment to the local inhabitants.

\section{References:-}

1. Agbaire, P.O. and Esiefarienhe, E. (2009). Air Pollution tolerance indices (APTI) of some plants around octorogun gas plant in delta state, Nigeria .J. Appl. Sci. Environ .Mgt .13 (1) : 11-14

2. Agrawal, M., Narayan, D., Singh, S.K. and Rao, D.N. (1991). Air pollution tolerance index of plants J. Envirommgt 32: 45-55

3. Agrwal M.J., Singh, B.J. Rajput, M.J .Marshall, F. And Bell, J.N.B. (2003) Effect of Air Pollution on peri urbar agriculture Journal of Environment pollution 126(23): 323-329

4. Anda, A. (1986) Effect of cement kiln dust on the radiation balance and yields of plants Env poll., $40: 249$ 256

5. Ashender, T.W. and Williams, I.A.D. (1980). Growth reduction in loliummultiflorum lam and pheum pretense L as a result of Sulphur dioxide and nitrogen dioxide pollution. Env. Poll. 21:131-139.

6. Chandawat, D. K, Verma PV, Solanki HA (2011) Air Pollution tolerance index (APTI) of tree species at cross roads of Ahmedabad city. Life science leaflets. 20: 935 - 943

7. Chen Y.M.J. Lucas, P and Wellburn, A.R. (1990). Relative relationship between foliar injury and change in antioxidants level in red and Norway spruce exposed to acidc mists. Environ pollut. 69(10) 1-15.

8. Das, S. and Prasad, P. (2010). Evaluation of expected performance index for some tree and shrub species in and around Raurkela. India j.env.prot.,30(8) : 635-642

9. Das, S. et al., (2010). Air pollution tolerance index (APTI) of various plant species growing in industrial areas of Raurkela. India j.Env.Prot. 30(7): $: 563-567$

10. Dedio, W., (1975). Water relations in what leaves as screening test for drought resistance, Canadian journal of plant science, 55(2): $369-378$

11. Escobedo, F.J., Wagner, J.E. and Nowak, D.J. (2008). Analyzing the cast effectiveness of Santiago chile's policy of using urban forest to improve air quality of environmental management, $86: 148-291$.

12. Gharge, S. and Menon, G.S. (2012). Air pollution tolerance index (APTI) or certain herby from the site around Ambernath MIDC Asian J. Exp. Bio Sci. 3(3) : $543-547$

13. Jyoti J.S., Jaya, D.S. (2010). Evaluation of air pollution tolerance index of selected plant species along road sides in thiravananthapuram, Kerla. J. Environ Bio 31: $379-386$

14. Katiyar, V. and Dubey, D.S. (2001). Sulpghur Dioxide Sensitirity on two stage of leaf development in a few tropical tree species, Ind .j. Envirom. Toxicol 11 (2), 78-81

15. Lakshmi, P.S., Saraswati, K.L. And Srinivas, N. (2009). Air pollution tolerance index of various plant species growins in industrial area. Soumal of Environmental Science, 2: 203-206

16. Meerabai, G., Venkata, R.C. and Rasheed, M. (2012). Effect of Industrial pollution on physiology of cajanuscajan (L.) fabaceae. Int J. Enviromsci 2 (4): 1889 - 1894.

17. Mejstrik, V. (1980) the influence of low $\mathrm{SO}_{2}$ concentration on growth reduction of ntcotinatabacum L.W Samsum and Cucumissativus L cvunikat, Env, poll. $21: 73-76$

18. Pierrem and Queirzq.( 1981). Enzymic and metabolic changes in bean leaves during continuous pollution by necrotic level of $\mathrm{So}_{2}$ Environ pollut, 25: 41-51. 
19. Rai P.K., Panda L.L.S., Chutia, B.M. and Singh, M.M. (2013). Comparative assessment of air pollution tolerance index (APTI) in the industrial (Rourkela) and industrial area (AIZAVL) of India: An eco management approach AFR J Environ sci techno 7(10).

20. Raina, A.K. and Sharma, A. (2003). Effects of vehicular pollution on the leaf micro -orphology, anatomy and chlorophyll contents of syzygiumcumini L.Indian J.Env.prot., 23(8): 897-902

21. Scholz, F. and Rick, S. (1977). Effects of acid on forest tress as measured by titration in vitro, inhebitance of buffering capacity in piceaabies, water, air and soil pollution, 8, 1977: 41-45

22. Singh, S.K. and Rao, D.N. (1983), Evaluation of plants for their tolerance to air pollution in Air pollution control in Delhi. Proceedings pp 218-224

23. Singh, S.N. and Verma, A. (2007). Phytoremediation of Air pollution a review in environmental Bioremediation Technology, singh S.N and Tripathy, R.D (eds) Spinger, Berlin Heidelberg PP - 293 -314

24. SuvarnaLakshmi,P. Lalithasravante, K. and Srinivas,N. (2008). Air pollution tolerance index of various plant species grouvings in industrial area, the Ecoscan, 2(2): 203-206

25. Thambavani, S.D. and Sabitha, M.A. (2011). Variation Air pollution tolerance index and anticipated performance index of plants near a sugar Factory: Implications of landscape plant species selection of industrial areas. Journal of Research in biology-7:494-502

26. Wagh N.D; Shukla P.V; Tambe S.B; Ingle S.T.(2006), Biological monitoring of roadside plants exposed to vehicular pollution in Jaigaon city. Journal of Environmental Biology 27(2): 419-421

27. Yan Ju, L. and Hui, D.(2008). Variation in Air Pollution tolerance index of plant near a steel factory; Implication for and scape -plant species selection for industrial areas, WSEAS Trains. Environmental and Development, 4(1), $24-30$ 